\title{
Reliability and validity of the novel Italian version of the 14-item Resilience Scale (RS-14) in adults
}

\author{
Sofia Cuoco ${ }^{1} \cdot$ Immacolata Carotenuto $^{1}$ - Arianna Cappiello ${ }^{1} \cdot$ Rossella Bisogno $^{1} \cdot$ Marina Picillo $^{1}$. \\ Maria Teresa Pellecchia ${ }^{1} \cdot$ Paolo Barone ${ }^{1} \cdot$ Roberto Erro $^{1}$ (1)
}

Received: 22 September 2021 / Accepted: 24 November 2021 / Published online: 30 November 2021

(c) Fondazione Società Italiana di Neurologia 2021

\begin{abstract}
Background The aims of this explore the psychometric properties of the novel Italian version of the 14-item Resilience Scale (RS-14) and to assess the relationship between RS-14, mood and quality of life.

Method The original English version of the RS-14 was translated into Italian, and the Italian version was confirmed with back-translation. Three-hundred healthy volunteers $(M=122)$ aged $>18$ years, completed the RS-14 as well as different scales to measure depression, anxiety and quality of life. Statistical analyses were used to measure the reliability, validity and key factors of RS-14. We measured the differences in socio-demographic subgroups, the relationship between mood and RS-14 score and the impact of RS-14 on mental health.

Results The RS-14 showed good acceptability, reliability and validity. Factor analysis indicated a two-factor structure: 'Selfconfidence' and 'Self-control', with the former having a more significant impact on mental health. The RS-14 score was not significantly different for sex, age and education, but there was significant difference for marital status. Lower resilience correlated with higher levels of anxiety and depression and with lower quality of life.

Conclusion We propose the novel Italian version of the RS-14 which has good reliability and validity. Our results stress the influence of resilience on mental health.
\end{abstract}

Keywords Aging $\cdot$ Depression $\cdot$ Mental health $\cdot$ Psychometric properties $\cdot$ Quality of life $\cdot$ Resilience scale

Roberto Erro

rerro@unisa.it

Sofia Cuoco

scuoco@unisa.it

Immacolata Carotenuto

carotenutoimma@gmail.com

Arianna Cappiello

acappiello@unisa.it

Rossella Bisogno

dottoressabisogno@gmail.com

Marina Picillo

mpicillo@unisa.it

Maria Teresa Pellecchia

mpellecchia@unisa.it

Paolo Barone

pbarone@unisa.it

1 Neuroscience Section, Department of Medicine, Surgery and Dentistry 'Scuola Medica Salernitana', University of Salerno, Via Allende, SA 84131 Baronissi, Italy

$\begin{array}{ll}\text { Abbreviations } \\ \text { BP } & \text { Bodily pain } \\ \text { COVID } & \text { COronaVIrus Disease 19 } \\ \text { EEG } & \text { Electroencephalography } \\ \text { EQ-VAS } & \text { Visual analogue scale } \\ \text { EQ-5D } & \text { EuroQoL 5-dimensions } \\ \text { F } & \text { Female } \\ \text { GH } & \text { General health } \\ \text { HADS } & \text { Hospital Depression Anxiety Rating Scale } \\ \text { ICC } & \text { Intraclass correlation coefficient } \\ \text { IQR } & \text { Interquartile range } \\ \text { M } & \text { Males } \\ \text { MH } & \text { Mental health } \\ \text { MMSE } & \text { Mimi Mental State Examination } \\ p & p \text { Value } \\ \text { PD } & \text { Parkinson disease } \\ \text { PF } & \text { Physical functioning } \\ \text { RE } & \text { Role emotional } \\ \text { RP } & \text { Role physical } \\ \text { RS } & \text { Resilience Scale } \\ \text { SD } & \text { Standard deviation }\end{array}$


SF Social functioning

SF-36 Short Form Health Survey 36 item

SPSS Statistical Package for Social Science

VT

Vitality

\section{Introduction}

Resilience is the human ability to cope with difficult, stressful and traumatic situations while maintaining or restoring normal functioning [1]. Resilience is not an innate capacity [1], but it is a dynamic and modifiable process, gradually developed through life by facing and overcoming adverse events [2]. It has been construed to be composed of seven factors: optimism, acceptance, focus on problem solving, defense mechanisms, forgiveness, responsibility, acquaintance and planning for the future. Resilient subjects are characterized by optimistic view, constructive criticism, good relationships with others, social skills and emotional awareness [1,3]. Resilience represents a complex set of protective and salutogenic factors, and it can be used to better understand health and illness, treatment and healing processes, including co- and multi-morbidities [2]. In fact, it is linked with mental health, well-being and quality of life (QoL), and its factors modulate the relationship between stress, trauma and/or illness and positive outcomes $[2,4,5]$. Higher resilience is associated to lower vulnerability, risk of diseases and multimorbid conditions and predicts positive adaptation to chronic conditions [1, 6-8].

Among chronic conditions, neurological disorders are emergingly raising as prevalent conditions with scarce therapeutic options in most cases. In 2010, neurological disorders accounted for $3 \%$ of all global disease-related disability-adjusted life years (DALYs), a 17\% increase since 1990 , much of which is attributed to the overall aging of the global population [9, 10]. In 2015, stroke and Alzheimer's and other types of dementia were the second and third leading causes of DALYs, respectively, in the population aged $>80$ years [10]. In this context, it seems advisable to adopt alternative approaches to help patients and their caregivers adapting to live with chronic conditions. In the last years, resilience has been in fact increasingly studied in several neurologic conditions. Robottom et al. [11] found that in Parkinson disease (PD), resilience correlated with lower motor and non-motor disability and better quality of life. Furthermore, we recently demonstrated that lower resilience levels predicted higher traumatic consequences and poorer health-related QoL (HRQoL) in PD patients following the COVID-19 pandemic [8]. In a sample of subjects with epilepsy, greater resilience was associated with better seizure control, normal EEG background activity and antiepileptic drug monotherapy. Moreover, higher resilience correlated with lower depressive episodes and better performance in the MiniMental State Examination (MMSE), resulting in higher QoL [12].Finally, resilience has been suggested to reduce caregiver burden in both dementia [13] and PD [7]. In fact, it would allow caregivers to manage and respond positively to the highly stressful demands of care [14].

Mirroring the significant increase in resilience research [15], a variety of tools have been developed for its measurement. However, some of these instruments lack evidence of appropriateness for administration to the general population [16]. One of the best scales to measure resilience is the Resilience Scale (RS) [17], which assesses five core dimensions of resilience: purpose, perseverance, self-confidence, equanimity and existential solitude (authenticity) $[4,18,19]$. The RS has been subsequently revised by one of the original authors in 2009 [20] in a novel shorter version, consisting of 14 items (RS-14), which has been shown to be as accurate as the original version to measure resilience levels. The RS-14 has been therefore widely used $[16,18,21]$ because of a number of advantages with respect to other resilience scales, including ease of use, applicability in different age groups ranging from adolescent to elderly, basic constructs focused on positive psychological qualities rather than deficits and good psychometric properties [22]. The RS-14 is constituted by 14 items and for each subject is requested to declare the agreement on a 7-point Likert-type scale. With its maximum being 98 , a score $<56$ indicates a very low level of resilience [20]. The RS-14 has been subsequently translated and validated in several languages, including Italian [23]. Although the Italian version of RS-14 showed overall good validity and reliability, it was also shown that the item 12 ('In an emergency, I am someone people can generally rely on') could not be grouped with any other items in a factor analysis. In fact, Miroševič et al. [24] found that, differently from all other versions, it was the only study identifying in the factor analysis three factors of the RS-14. Having used the Italian version of the RS-14 in our own research, we come across a mistake in the translation of the RS-14 by Callegari et al. [23] related indeed to item 12, which could be likely explaining the findings detailed above. Moreover, the study by Callegari et al. [23] also has some limitations regarding the characteristics of the recruited sample: in fact, $75 \%$ of the sample was composed of young adults below the age of 24 years, and it was unbalanced in terms of sex distribution with almost $90 \%$ of the sample being females. A more evenly distributed sample could help clarify the debate on the relationship between resilience and sex [17, 25-28].

For these reasons, we aimed: (1) to explore the psychometric properties of novel translation of the RS-14 in adult Italian sample, homogeneously distributed for the variable sex and with a better representation of middle-aged and older adults; and (2) to assess the relationship among RS-14, mood and quality of life. 


\section{Methods}

\section{Participants and assessments}

Healthy volunteers aged $>18$ years, with no history of any neurological or psychiatric conditions and not taking any drugs acting on the nervous system, were invited to participate to this study, after providing their written informed consent. The project was performed in accordance with the ethical standards laid down in the 1964 Declaration of Helsinki and was approved by the local Ethics Committee.

Data were collected on an encrypted online platform. Students of the medical school of the University of Salerno were invited to involve their parents/family members to participate in the study. They were provided with a link to get access to the online questionnaires and scales. The first page contained information about the aims of the study, a consent form, as well as information about personal data handling (anonymity) and the time needed to complete the questionnaires of about $20 \mathrm{~min}$. Respondents had to give their informed consent before they could start completing the questionnaires.

The following data were gathered: age, sex, years of education (junior high school/senior high school/university degree or higher), marital status (single/non-single), presence of any medical conditions, current pharmacological treatments. Moreover, subjects were requested to complete the RS-14, the Hospital Depression Anxiety Rating Scale (HADS) to assess depression and anxiety, the EuroQol 5D (EQ-5D) and the EQ-VAS to investigate HR-QoL and the Short Form Health Survey 36 item (SF36) to assess QoL.

The original English version of the RS-14 was translated into Italian by one of the authors who is fluent in English (RE) and subsequently back-translated by a native English speaker (SA) who is fluent in Italian. There were no significant differences between the two English versions (original and back-translated). The novel Italian translation of the RS-14 is displayed in Appendix.

\section{Statistical analysis}

All analyses were performed by SPSS for Windows, version 23.0. All statistical tests were two-tailed, with alpha set at 0.05 . A descriptive analysis was used to study the frequency distribution of all variables of interest, and the Mann-Whitney test was used to analyze the differences between males and females in terms of age and education.

The following psychometric properties were explored for the RS-14 total score: acceptability, internal consistency and construct validity. Acceptability was considered appropriate for each RS-14 item if there were $\leq 5 \%$ of missing values and for the total score if there were $\leq 15 \%$ of the lowest and highest possible scores (floor and ceiling effect). Moreover, skewness of total (limits, -1 to +1 ) was determined. Internal consistency was evaluated by means of Cronbach's alpha. A value $\geq 0.70$ was considered acceptable. Scaling assumptions referring to the correct grouping of items and the appropriateness of their summed score were checked using corrected item-total correlation for RS-14 (standard, $\geq 0.40$ ).

Construct validity was explored with Spearman's correlation between RS-14 and the other administered scales. Namely, we used the EQ-5D total score, the HADS total score and its subscores, as well as physical functioning (PF), bodily pain (BP), general health $(\mathrm{GH})$, vitality (VT) and mental health $(\mathrm{MH})$ scores of the SF-36. Correlations were considered strong with coefficients $>0.70$ and moderate with a coefficients between 0.30 and 0.70 .

We also determined the reliability of the RS-14 in terms of absolute (i.e. the extent to which the scores remain the same across time or situations) and relative stability (i.e. the degree to which the relative differences in scores among individuals remain the same over time). In order to assess absolute stability, the paired Wilcoxon test was used to compare the mean RS-14 score at baseline and follow-up. To determine the magnitude of these differences in addition to their statistical significance, Cohen's d for within-subjects comparisons with the paired Wilcoxon test was calculated correcting for dependence between means. Subsequently, in order to examine the relative stability of the RS-14 score, the intraclass correlation coefficient (ICC) between RS-14 on the first and second administration was computed.

Subsequently, we conducted a factor analysis, with Varimax rotation, to examine the factor structure of RS-14.

Where necessary, the Mann-Whitney and Kruskal-Wallis tests were used to measure the differences in RS-14 between socio-demographic subgroups. Where necessary, post hoc analyses were performed using pairwise Mann-Whitney test, $p<0.05$ being deemed significant.

Mann-Whitney test was used to compare patients stratified according to the median score of RS-14 for mood symptoms, as assessed by the HADS.

Finally, to explore whether RS-14 score, could affect the level of mental health, a logistic multinomial regression analysis, with bootstrap method, was performed with SF-36 MH as the dependent variable and controlling for socio-demographic variables that resulted significant in the Mann-Whitney and/or Kruskal-Wallis test analyses, $p<0.05$ deemed significant. Specifically, we used SF-36 MH as dichotomic variable, by grouping the scores above and below the median value. Subsequently, to explore which of the factors obtained by factor analysis impacted the most 
on SF-36 MH, we conducted a linear regression with the Bootstrap method.

\section{Results}

\section{Sample characteristics}

Three-hundred-twelve subjects were invited to participate and completed the assessments. Of these, 12 were excluded because of the presence of a neurological or psychiatric condition. Therefore, 300 subjects (178 females, 59.3\%) with a mean $( \pm S D)$ age of $42.41 \pm 13.11$ years and mean $( \pm$ SD) education of $14.86 \pm 4.27$ years were included in the analysis. Male and female subjects did not differ for age and education (age, $U=10,306, p=0.45$; education, $U=5965.5$, $p=0.52$ ) (see Table 1 for the socio-demographic data of the entire sample).

Fifty subjects $(26 \mathrm{~F}, 52 \%)$ were asked to completed the RS-14 for a second time after about 4 weeks: they did not significantly differ on any socio-demographic variables nor in terms of resilience and quality of life from the 250 participants who completed the RS-14 only at baseline (data not shown, for all $p>0.05$ ).

\section{Acceptability}

The mean $( \pm$ SD) RS-14 total score was $82.34 \pm 10.70$. One-hundred percent of data were totally computable,

Table 1 Participants' characteristics

\begin{tabular}{lll}
\hline & $N(\%)$ & $\begin{array}{l}\text { RS-14 total score } \\
\text { median (IQR) }\end{array}$ \\
\hline $\begin{array}{ll}\text { Sex } \\
\quad \text { Male }\end{array}$ & $122(40.7)$ & $87(14)$ \\
$\quad$ Female & $178(59.3)$ & $83(13)$ \\
Age & & \\
$\quad<30$ & $65(21.6)$ & $81(15)$ \\
$31-40$ & $85(28.4)$ & $85(14)$ \\
$41-50$ & $69(23)$ & $86(14)$ \\
$51-60$ & $46(15.4)$ & $83(15)$ \\
$\quad>60$ & $35(11.6)$ & $86(17)$ \\
Marital status & & \\
$\quad$ Single & $144(48)$ & $81(14)$ \\
$\quad$ Non- single & $156(52)$ & $86(12)$ \\
Education & & \\
$\quad$ Junior high school & $38(12.6)$ & $83(15)$ \\
Senior high school & $109(36.4)$ & $86(14)$ \\
$\quad$ University degree or higher & $153(51)$ & $84(14)$ \\
\hline
\end{tabular}

Abbreviations: $I Q R$ interquartile range, $N$, number, $R S-14$ the 14 -item Resilience Scale and there were no missing values. In the entire sample, neither the ceiling nor the floor effects were observed for the RS-14 total score (lowest possible score $=35$, $0.3 \%$; highest possible score $=98,3.3 \%$ ). The skewness of RS-14 was within the standard limits (RS-14 total score $=-1.02$ ).

\section{Reliability}

Cronbach's alpha was 0.897 , and, thus, it was considered acceptable for internal consistency. No item improved Cronbach's alpha if removed. Item RS- 14 correlation was $\geq 0.45$ for all questions (Table 2).

\section{Convergent and divergent construct validity}

As for the RS-14, the Spearman's correlation showed no relation with education $(\mathrm{rho}=-0.05, p=0.47)$ and a low correlation with age $(\mathrm{rho}=0.18, p=0.001)$. A moderate correlation emerged with SF-36 MH,HADS-D, SF-36 VT, HADS-Total score, SF-36 RE, SF-36 SF, HADS-A, EQVAS, EQ-5D. A low correlation emerged with SF-36 GH, SF-36 RP, SF-36 BP and SF-36 PF (Table 3).

\section{Absolute and relative stability}

Regarding absolute stability of RS-14, the Wilcoxon test showed no significant difference between the RS-14 score at baseline compared with follow-up $(z=-1.79, p=0.09)$. The ICC between scores on the first and second administration was $0.93(0.86-0.96$, confidence interval for $95 \% ; p<0.001)$. The Cohen's $d$ for within-subjects was $0.17(p<0.001)$. At follow-up, the $76 \%$ of 50 subjects differed only \pm 5 points by baseline RS-14 score.

\section{Factor analysis}

All 14 questionnaires were deemed appropriate for factor analysis, since the Kaiser-Meyer-Olkin (KMO) measure was 0.91. In addition, Bartlett's test was $1704.09(p<0.001)$, indicating that the data satisfied the conditions for factor analysis. The factor analysis disclosed two factors with eigen values greater than 1.0, and the visual inspection of the screen plots confirmed the presence of two factors, of which the first loads items 11,10,13, 4, 14, 12 and the second items 5, 3, 6, 7, 1, 8, 9, 2 (Table 2). All 14 items showed factor loadings greater than 0.45 and less than -0.45 . Factor loadings for Factor 1 were between 0.50 and 0.80. Factor loadings for Factor 2 were between 0.49 and 0.73 . The total variance explained by the extracted factors was $50.67 \%$. The variance explained by Factor 1 was $26.23 \%$ and by Factor 2 was $24.44 \%$. The items loading on Factor 1 relate to trust and confidence in life, and so this factor was named 
Table 2 Spearman's correlation analysis between the total score of the RS-14 and each item (left) and results obtained by factor analysis (right)

\begin{tabular}{|c|c|c|c|}
\hline & $\begin{array}{l}\text { Correlations } \\
\text { between } \\
\text { the total score of the } \\
\text { RS-14 } \\
\text { and each item }\end{array}$ & $\begin{array}{l}\text { Factor 1: } \\
\text { Self-confidence }\end{array}$ & $\begin{array}{l}\text { Factor 2: } \\
\text { Self-control }\end{array}$ \\
\hline 1. I usually manage one way or another & $.54 *$ & & .561 \\
\hline 2. I feel proud that I have accomplished things in life & $.68 *$ & & .490 \\
\hline 3. I usually take things in stride & $.67 *$ & & .660 \\
\hline 4. I am friends with myself & $.72 *$ & .703 & \\
\hline 5. I feel that I can handle many things at a time & $.61 *$ & & .726 \\
\hline 6. I am determined & $.68 *$ & & .653 \\
\hline 7. I can get through difficult times because I have experienced difficulty before & $.59 *$ & & .582 \\
\hline 8. I have self-discipline & $.65^{*}$ & & .539 \\
\hline 9. I keep interested in things & $.63^{*}$ & & .512 \\
\hline 10. I can usually find something to laugh about & $.59 *$ & .782 & \\
\hline 11. My belief in myself gets me through hard times & $.79 *$ & .802 & \\
\hline 12. In an emergency, I am someone people can generally rely on & $.46^{*}$ & .497 & \\
\hline 13. My life has meaning & $.66^{*}$ & .724 & \\
\hline 14. When I am in a difficult situation, I can usually find my way out of it & $.65^{*}$ & .527 & \\
\hline
\end{tabular}

Abbreviations: $R S$ - 14 the 14-item Resilience Scale

${ }^{*} p<.001$

Table 3 Convergent validity of the RS-14

\begin{tabular}{lll}
\hline RS-14 & & \\
\hline & Rho & $p$ \\
\hline SF-36 MH (mental health) & .58 & $<.001$ \\
HADS-Depression & -.51 & $<.001$ \\
SF-36 VT (vitality) & .49 & $<.001$ \\
HADS-Total score & -.48 & $<.001$ \\
SF-36 RE (role emotional) & .37 & $<.001$ \\
SF-36 SF (social functioning) & .36 & $<.001$ \\
HADS-Anxiety & -.36 & $<.001$ \\
EQ-VAS & .33 & $<.001$ \\
EQ5D-Total score & -.32 & $<.001$ \\
SF-36 GH (general health) & .27 & $<.001$ \\
SF-36 RP (role physical) & .25 & $<.001$ \\
SF-36 BP (bodily pain) & .21 & $<.001$ \\
SF-36 PF (physical functioning) & .13 & $<.001$ \\
\hline
\end{tabular}

Statistically significant results are indicated in bold. Abbreviations: $B P$ bodily pain, $E Q-V A S$ visual analogue scale, $E Q-5 D$ EuroQoL 5-dimentions, $G H$ general health, $H A D S$ Hospital Depression Anxiety Rating Scale, $M H$ mental health, $p p$ value, $P F$ physical functioning, $R E$ role emotional, $R P$ role physical, $R S$ Resilience Scale, $S F$ social functioning, $S F-36$ Short Form Health Survey 36 item, $V T$ vitality

Self-confidence. The items loading on Factor 2 relate to selfcontrol and the ability to manage independently. This factor was therefore named Self-control. The correlation between the two factors was rho $=0.05(p=0.45)$. Cronbach's alpha of Factor 1 was 0.837 and of Factor 2 was 0.825 , being therefore acceptable for internal consistency.

\section{Distribution of RS-14 on socio-demographic subgroups}

The Mann-Whitney and Kruskal-Wallis tests showed that the RS-14 score was not significantly different for sex, age and education $(p>0.05)$. There was a significant difference for marital status (81 (14) vs 86 (12), single vs non-single, respectively; $U=8683, p=0.001$ )) (see Table 1 for median (IQR) of RS-14 according to socio-demographic variables).

\section{Resilience, mood and quality of life}

The Mann-Whitney test analysis showed that subjects with lower resilience (RS-14 score $\leq$ median of 84 ) had higher mood symptoms assessed by HADS than subjects with higher resilience (HADS-Total score: 14 (8) vs 9 (6), $U=6151, p<0.001$; HADS-D: 6.5 (5) vs 3 (3.5), $U=5780$, $p<0.001$; HADS-A: 7(5) vs $6(3), U=7563.5, p<0.001)$.

Finally, to explore whether RS-14 score, adjusted for marital status, could predict the level of mental health, a logistic multinomial regression analysis was performed, $p<0.001$ deemed significant. The RS-14, used as a dichotomous variable, i.e. by grouping the lower and higher scores to the median value $(B=1.96, \operatorname{Exp}(B)=7.09, p=0.001)$, but not marital status, used as covariate $(B=0.20, \operatorname{Exp}(B)=1.22$, 
$p=0.46)$, significantly affected the mental health, explaining about $25 \%$ of the variance $\left(R^{2}=0.25\right)$.

To explore the specific role of RS-14 factors on mental health, a linear regression analysis was performed, $p<0.001$ deemed significant and $F$-value equal to 82.48 . The Factor $1(B=9.64, \operatorname{Exp}(B)=0.53, p=0.001)$ and the Factor 2 $(B=5.19, \operatorname{Exp}(B)=0.28, p=0.001)$ significantly affected the mental health and together explain about $35 \%$ of the variance $\left(R^{2}=0.35\right)$.

\section{Discussion}

We here provided the novel Italian version of the RS-14, demonstrating that it has good psychometric properties comparable to the original version. As reported in some international studies about RS-14 [29-31] but in opposition to others [19, 32, 33], we found two factors that we named Self-confidence and Self-control, as in a previous study [29]. As mentioned above, Callegari et al. [23] found a threefactor solution, with the validity of the construct being unacceptable, which they attributed to the homogeneity of the sample that mostly included young, single, female students. However, we hypothesize that the wrong translation of one the RS-14 items may have affected this result. On the other hand, the differences in factor structure found across studies may reflect cultural differences in the understanding of the resilience concept. In our study, the total variance of our study was satisfactory, and the inter-factor correlation was less than 0.50 ; therefore, factors can be considered independent from each other.

The scale as a whole showed high acceptability since data were computable for the entire sample. The acceptability of the RS-14 is also supported by the absence of both ceiling and floor effects. The internal consistency of the RS-14 has been shown high and acceptable (alpha $=0.897)$. The RS-14 total score had moderate correlation with all items. As for convergent and divergent construct validity, we found unnoticeable associations of the RS-14 with demographics, education and age. Such low correlations can be indicative of a satisfactory divergent validity and suggests that the scale is suitable for Italian people of any age and education. The low correlation between RS-14 and physical functioning bodily pain and general health confirms the limited relevance of resilience in these constructs, which are more physical and less mental. On the other hand, the adequate construct validity of the RS-14 is supported by a moderate correlation with health status, depression, anxiety, vitality and mental health. These findings support the hypothesis that mood and mental health are more related to resilience than other features such as age, education, physical and general health [1, 3]. The temporal and absolute stabilities of RS-14 scores were also found to be good. The ICC in our study was high
(0.929), which could be explained by the large sample size representative of different age groups. In fact, it seems that the novel Italian translation of the RS-14 has good reliability in adults. It should be noted, however, that the age group above 60 years was not largely represented (about $12 \%$ of the entire sample). Although we did not find any age effect on resilience levels, which is in line with the original study by Wagnild and Young [17], a further validation of the Italian RS-14 might be required in the elderly considering the potential effect of age on resilience that has been suggested by some authors $[25,28,34,35]$.

Similarly, we did not find any differences between male and females in line with previous evidence [17, 28]. However, other studies found that males show greater resilience than females [25-27]. It should be noticed, however, that most of these studies recruited a sample which was very unbalanced in terms of sex distribution, and this might have affected the results.

We did not find a significant relationship between education and resilience; these data are in line with the evidence that schooling is not considered to modulate resilience $[1,3]$ and would rather support the relationship between emotional intelligence and resilience [36]. However, there are heterogeneous findings about the interaction between education and resilience [17, 26, 35, 37]. Although we acknowledge that subjects with low education were slightly under-represented in our study, we also note that the comparison between subjects with senior high school level and with University degree or higher was not significant and that there was no correlation between resilience levels and years of schooling, which support the consistency of our findings. Nonetheless, other studies with higher percentages of subjects with low education may be useful to definitively clarify this aspect.

In our sample, singles had lower resilience than nonsingles, which is in line with research demonstrating that social support increases resilience and maintains well-being [38]. Finally, we showed that subjects with lower resilience had higher depression and anxiety symptoms in line with previous evidence demonstrating that mood dysfunction is negatively associated with trait resilience [21, 35, 39]. Moreover, we found that resilience predicted mental health. Although both factors found in the factorial analysis significantly influenced mental health, Self-confidence was more heavily strictly related to mental health than Self-control. In accordance with the cascade model, certain resilience factors can contribute to the development of others. Therefore, it is conceivable that the Self-confidence factor contributes to the Self-control factor. Furthermore, the Self-confidence factor is more associated with primary resilience which is related to maintaining equilibrium and health, and preventing stress. While the Self-control factor is associated with secondary resilience, linked to processes and behaviors 
aimed at reducing stress and restoring health and psychophysical equilibrium [1].

Therefore, we support a preventive work that may increase the capacity of the subjects to have a Self-confidence attitude about their skills and abilities, accept themselves, know their strengths and weakness well and have a positive view of yourself, setting realistic expectations and goals, communicating assertively and handling criticism.

In summary, we here provided a novel Italian translation of the RS-14 that can be used in both future research and clinical settings.

\section{Appendix: La Scala della Resilienza a 14 item (RS-14)}

Per favore legga le seguenti affermazioni. Per ciascuna indichi il suo grado di accordo, cerchiando il numero sulla scala da 1 a 7 , dove 1 indica che per quell'affermazione lei è fortemente in disaccordo e 7 indica che è fortemente d'accordo.

\begin{tabular}{|c|c|c|c|c|c|c|c|}
\hline & $\begin{array}{l}\text { Fortemente } \\
\text { in disac- } \\
\text { cordo }\end{array}$ & & & & & & $\begin{array}{l}\text { Forte- } \\
\text { mente } \\
\text { in }\end{array}$ \\
\hline $\begin{array}{l}\text { 1. Di solito riesco } \\
\text { a cavarmela in un } \\
\text { modo o nell'altro }\end{array}$ & 1 & 2 & 3 & 4 & 5 & 6 & 7 \\
\hline $\begin{array}{l}\text { 2. Mi sento } \\
\text { orgoglioso/a per } \\
\text { le cose che ho } \\
\text { realizzato nella } \\
\text { mia vita }\end{array}$ & 1 & 2 & 3 & 4 & 5 & 6 & 7 \\
\hline $\begin{array}{l}\text { 3. Solitamente } \\
\text { affronto le cose } \\
\text { senza farmi } \\
\text { sovrastare dagli } \\
\text { eventi }\end{array}$ & 1 & 2 & 3 & 4 & 5 & 6 & 7 \\
\hline $\begin{array}{l}\text { 4. Sono amico/a di } \\
\text { me stesso/a }\end{array}$ & 1 & 2 & 3 & 4 & 5 & 6 & 7 \\
\hline $\begin{array}{l}\text { 5. Sento di poter } \\
\text { gestire molte } \\
\text { cose allo stesso } \\
\text { tempo }\end{array}$ & 1 & 2 & 3 & 4 & 5 & 6 & 7 \\
\hline $\begin{array}{l}\text { 6. Sono } \\
\text { determinato/a }\end{array}$ & 1 & 2 & 3 & 4 & 5 & 6 & 7 \\
\hline $\begin{array}{l}\text { 7. Posso affrontare } \\
\text { momenti difficili } \\
\text { perché ho già } \\
\text { affrontato delle } \\
\text { difficoltà in pas- } \\
\text { sato }\end{array}$ & 1 & 2 & 3 & 4 & 5 & 6 & 7 \\
\hline $\begin{array}{l}\text { 8. Ho auto-disci- } \\
\text { plina }\end{array}$ & 1 & 2 & 3 & 4 & 5 & 6 & 7 \\
\hline $\begin{array}{l}\text { 9. Mantengo inter- } \\
\text { esse nelle cose }\end{array}$ & 1 & 2 & 3 & 4 & 5 & 6 & 7 \\
\hline
\end{tabular}

\begin{tabular}{|c|c|c|c|c|c|c|c|}
\hline & $\begin{array}{l}\text { Fortemente } \\
\text { in disac- } \\
\text { cordo }\end{array}$ & & & & & & $\begin{array}{l}\text { Forte- } \\
\text { mente } \\
\text { in }\end{array}$ \\
\hline $\begin{array}{l}\text { 10. Di solito trovo } \\
\text { qualcosa per cui } \\
\text { sorridere }\end{array}$ & 1 & 2 & 3 & 4 & 5 & 6 & 7 \\
\hline $\begin{array}{l}\text { 11. II credere in } \\
\text { me stesso/a mi } \\
\text { aiuta a superare i } \\
\text { momenti difficili }\end{array}$ & 1 & 2 & 3 & 4 & 5 & 6 & 7 \\
\hline $\begin{array}{l}\text { 12. In una } \\
\text { situazione di } \\
\text { emergenza, io } \\
\text { sono qualcuno } \\
\text { su cui le persone } \\
\text { possono general- } \\
\text { mente contare }\end{array}$ & 1 & 2 & 3 & 4 & 5 & 6 & 7 \\
\hline $\begin{array}{l}\text { 13. La mia vita è } \\
\text { piena di signifi- } \\
\text { cato }\end{array}$ & 1 & 2 & 3 & 4 & 5 & 6 & 7 \\
\hline $\begin{array}{l}\text { 14. In una situazi- } \\
\text { one di difficoltà } \\
\text { riesco di solito a } \\
\text { trovare un modo } \\
\text { per uscirne }\end{array}$ & 1 & 2 & 3 & 4 & 5 & 6 & 7 \\
\hline
\end{tabular}

Acknowledgements We are grateful to Susan Ainscough for having participated in the translation of the RS-14 and for having edited the text.

Author contribution SC: substantial contributions to the conception or design of the work, analysis and interpretation of data for the work, drafting the work; IC: the acquisition of data for the work; AC: the acquisition of data for the work; RB: the acquisition of data for the work; MP: revising it critically for important intellectual content; MTP: revising it critically for important intellectual content; PB: revising it critically for important intellectual content; RE: substantial contributions to the conception or design of the work, analysis and interpretation of data for the work, revising it critically for important intellectual content, final approval of the version to be published.

Data availability The datasets generated during and/or analyzed during the current study are available from the corresponding author on reasonable request.

Code availability Not applicable.

\section{Declarations}

Ethics approval The project was performed by the local Ethics Committee (Campania Sud).

Consent to participate Informed consent was obtained from all individual participants included in the study.

Consent for publication The participants signed informed consent regarding publishing their data. 
Conflict of interest The authors have no financial or proprietary interests in any material discussed in this article. Dr Marina Picillo is supported by the Michael J Fox Foundation for Parkinson's research; Prof Paolo Barone received consultancies as a member of the advisory board for Zambon, Lundbeck, UCB, Chiesi, AbbVie, and Acorda; Dr Roberto Erro receives royalties for the publication of 'Case Series in Movement Disorders' (Cambridge University Press, 2017) and 'Paroxysmal Movement Disorders' (Springer, 2020); he received honoraria for speaking from the Movement Disorder Society. The other authors report no financial disclosures. Authors are responsible for correctness of the statements provided in the manuscript.

\section{References}

1. Babić R, Babić M, Rastović P, Ćurlin M, Šimić J, Mandić K, Pavlović K (2020) Resilience in health and illness. Psychiatr Danub 32(Suppl 2):226-232

2. Jakovljevic M (2017) Resilience, psychiatry and religion from public and global mental health perspective. Dialogueand cooperation in the search for humanistic self, compassionate society and empathic civilization. Psychiatr Danub 29:238-244

3. Luthar SS, Cicchetti D, Becker B (2000) The construct of resilience: a critical evaluation and guidelines for future work. Child Dev 71(3):543-562. https://doi.org/10.1111/1467-8624.00164

4. Masten A, Best K, Garmezy N (1990) Resilience and development: contributions from the study of children who overcome adversity. Dev Psychopathol 2:425-444

5. Maddi SR (2005) On hardiness and other pathways to resilience. Am Psychol 60:261-262

6. Kim GM, Lim JY, Kim EJ, Park SM (2019) Resilience of patients with chronic diseases: a systematic review. Health Soc Care Community 27(4):797-807

7. Klietz M, Drexel SC, Schnur T, Lange F, Groh A, Paracka L, Greten S, Dressler D, Höglinger GU, Wegner F (2020) Mindfulness and psychological flexibility are inversely associated with caregiver burden in Parkinson's disease. Brain Sci 10(2):111

8. Erro R, Cuoco S, Nigro E, Ragone R, Barone P (2021) Resilience and trauma among patients with Parkinson's disease during the COVID-19 pandemic. J Mov Disord 2021. https://doi.org/10. 14802/jmd.20126

9. Whiteford HA, Ferrari AJ, Degenhardt L, Feigin V, Vos T (2010) Global burden of mental, neurological, and substance use disorders: an analysis from the global burden of disease study 2010. In: Patel V, Chisholm D, Dua T, Laxminarayan R, Medina-Mora ME (eds) Mental, neurological, and substance use disorders: disease control priorities, third edition (volume 4). The International Bank for Reconstruction and Development / The World Bank, Washington (DC), Chapter 2

10. Kassebaum NJ, Arora M, Barber RM et al (2016) Global, regional, and national disability adjusted life-years (DALYs) for 315 diseases and injuries and healthy life expectancy (HALE), 19902015: a systematic analysis for the Global Burden of Disease Study 2015. The Lancet 388:1603

11. Robottom BJ, Gruber-Baldini AL, Anderson KE, Reich SG, Fishman PS, Weiner WJ, Shulman LM (2012) What determines resilience in patients with Parkinson's disease? Parkinson Relat Disord 18(2):174-177

12. Tedrus GMAS, Junior Limongi JM, Zuntini JVR (2020) Resilience, quality of life, and clinical aspects of patients with epilepsy. Epilepsy Behav 103(Pt A):106398

13. Wegner F (2020) Mindfulness and psychological flexibility are inversely associated with caregiver burden in Parkinson's disease. Brain Sci 10(2):111
14. Rosa RDLD, Simões-Neto JP, Santos RL, Torres B, Baptista MAT, Kimura NRS, Dourado MCN (2020) Caregivers' resilience in mild and moderate Alzheimer's disease. Aging Ment Health 24(2):250-258

15. Haskett ME, Nears K, Ward CS, McPherson AV (2006) Diversity in adjustment of maltreated children: factors associated with resilient functioning. Clin Psychol Rev 26:796-812

16. Ahern NR, Kiehl EM, Sole ML, Byers J (2006) A review of instruments measuring resilience. Issues Compr Pediatr Nurs $2: 103-125$

17. Wagnild GM, Young HM (1993) Development and psychometric evaluation of the Resilience Scale. J Nurs Meas 1:165-178

18 Wagnild GM (2009) The resilience scale user's guide for the US English version of the Resilience Scale and the 14-item Resilience Scale (RS-14). The Resilience Center, Montana

19. Losoi H, Turunen S, Wäljas M, Helminen M, Öhman J, Julkunen J, Rosti-Otajärvi E (2013) Psychometric properties of the Finnish version of the resilience scale and its short version. PCH $2: 1-10$

20. Wagnild G (2009) A review of the Resilience Scale. J Nurs Meas 17:105-113

21. Abiola T, Udofia O (2011) Psychometric assessment of the Wagnild and Young's resilience scale in Kano, Nigeria. BMC Res Notes 4:509

22. Baruth KE, Carroll JJ (2002) A formal assessment of resilience: the Baruth Protective Factors Inventory. J Indiv Psychol $58: 235-244$

23. Callegari C, Bertù L, Lucano M, Ielmini M, Braggio E, Vender $\mathrm{S}$ (2016) Reliability and validity of the Italian version of the 14-item Resilience Scale. Psychol Res Behav Manag 9:277-284

24. Miroševič Š, Klemenc-Ketiš Z, Selič P (2019) The 14-item Resilience scale as a potential screening tool for depression/anxiety and quality of life assessment: a systematic review of current research. Fam Pract 36(3):262-268

25. Bonanno GA (2004) Loss, trauma, and human resilience: have we underestimated the human capacity to thrive after extremely aversive events? Am Psychol 59:20-28

26. Bonanno GA, Galea S, Bucciarelli A, Vlahov D (2007) What predicts psychological resilience after disaster? The Role of Demographics, Resources, and Life Stress. J Consult Clin Psychol 75:671-682

27. Campbell-Sills L, Forde DR, Stein MD (2009) Demographic and childhood environmental predictors of resilience in a community sample. J Psychiatr Res 43:1007-1012

28. GirtlerN, De CarliF, AccardoJ, ArnaldiD, CutoloM, DessiB, FamàF, FerraraM, NobiliF, PiccoA, BrugnoloA (2014) Psychometric properties of the Italian version of resilience scale in adults and elderly healthy subjects. J Aging Res Clin Pract 3

29. Tian J, Hong JS (2013) Validation of the Chinese version of the resilience scale and its cutoff score for detecting low resilience in Chinese cancer patients. Support Care Cancer 21:1497-1502.24

30. Kwon HJ, Kwon SJ (2014) Korean version of the 14-Item Resilience Scale (RS-14) for university students: a validity and reliability study. J Korean Acad Psychiatr Ment Health Nurs 23(226-32):25

31. Sanchez Teruel D, Robles-Bello A (2015) 14-item Resilience Scale(RS-14): psychometric properties of the Spanish version. Rev Iberoam Diagn Ev 2:103-113

32. Aiena BJ, Baczwaski BJ, Schulenberg SE, Buchanan EM (2015) Measuring resilience with the RS-14: a tale of two samples. J Pers Assess 97:291-300

33. Ntountoulaki E, Paika V, Kotsis K et al (2017) The Greek version of the Resilience Scale (RS-14): psychometric properties in three samples and associations with mental illness, suicidality, and quality of life. JPCPY7: 1-10 
34. Recabal JEC, Leone PEF, Muñoz CAG, Escalona KSR, Díaz LAR (2012) Relisiencia y su relación com estilos de vida de los adultos mayores autovalentes. Cienc Enferm 18(3):73-81

35. Linnemann P, Wellmann J, Berger K, Teismann H (2020) Effects of age on trait resilience in a population-based cohort and two patient cohorts. J Psychosom Res 136:110170

36. Trigueros R, Padilla AM, Aguilar-Parra JM, Rocamora P, Morales-Gázquez MJ, López-Liria R (2020) The influence of emotional intelligence on resilience, test anxiety, academic stress and the Mediterranean diet. A Study with University Students. Int J Environ Res Public Health 17(6):2071

37. Friborg O, Hjemdal O, Rosenvinge JH, Martinussen M (2003) A new rating scale for adult resilience: what are the central protective resources behind healthy adjustment? Int J Methods Psychiatr Res 12:65-76
38. Cosco TD, Kaushal A, Richards M, Kuh D, Stafford M (2016) Resilience measurement in later life: a systematic review and psychometric analysis. Health Qual Life Outcomes 14:16

39. Laird KT, Krause B, Funes C, Lavretsky H (2019) Psychobiological factors of resilience and depression in later life. Transl Psychiatry 9(1):88

Publisher's note Springer Nature remains neutral with regard to jurisdictional claims in published maps and institutional affiliations. 